\title{
A Cross Sectional Study on Clinical and Radiological Profile of Sarcoidosis in a Tertiary Care Center in India
}

\author{
Vishwas Gupta ${ }^{1}$, Swapnil Manaji Thorve ${ }^{2}$, Pralhad Prabhudesai ${ }^{3}$ \\ ${ }^{1}$ Senior Resident, Department of Pulmonary Medicine, Gandhi Medical College and Hamidia Hospital, Bhopal, ${ }^{2}$ Assistant \\ Professor, Department of Pulmonary Medicine, Lokmanya Tilak Municipal Medical College, Sion, Mumbai, ${ }^{3}$ Consultant, \\ Department of Pulmonary Medicine, Lilavati Hospital and Research Centre, Mumbai, India
}

Corresponding author: Swapnil Manaji Thorve, Flat No 6, Second Floor, Shrinath Kripa Apartment, Near Hanuman Mandir, Kohefiza, Bhopal, Madhya Pradesh, 462001, India

DOI: http://dx.doi.org/10.21276/ijcmsr.2020.5.1.45

BY-NC-ND

How to cite this article: Vishwas Gupta, Swapnil Manaji Thorve, Pralhad Prabhudesai. A cross sectional study on clinical and radiological profile of sarcoidosis in a tertiary care center in India. International Journal of Contemporary Medicine Surgery and Radiology. 2020;5(1):A206-A210.

\section{A B S T R A C T}

Introduction:- Sarcoidosis is a global disease found in almost all continents. It is a multi-system disorder of unknown aetiology. sarcoidosis can involve almost all organs of body but lungs and the lymphatics are the common sites. Current study was done to study the clinicoradiological Profile of sarcoidosis in a tertiary care centre.

Material and Methods:-. This was a cross sectional observational study, includes 56 patients diagnosed to have sarcoidosis in department of pulmonary medicine in lilavati hospital and research centre, Bandra, Mumbai during the period 2015-2017 Results:- Average age of sarcoidosis was $46.07 \pm 6.06$ years, females comprised $64.28 \%$ of the patients. Before coming to our department, $42.9 \%$ patients had been misdiagnosed to have TB. Cough $(85.7 \%)$ was the most common presenting symptom; end inspiratory crepitations was seen in $50 \%$ patients. Cutaneous involvement were rarely seen. Pulmonary function testing showed restriction in $21.42 \%$ patients. The most common radiological feature was bilaterally symmetrical hilar lymphadenopathy.

Conclusions:- Sarcoidosis has clinical, radiological and serological manifestations which can vary. In developing countries with high prevalence of TB, like India, sarcoidosis is often misdiagnosed as TB. Hence, patients having chronic cough, bilateral hilar lymphadenopathy with or without infiltrates should be investigated for sarcoidosis.

Keywords: Sarcoidosis, Tuberculosis, Pulmonary Function Test.

\section{INTRODUCTION}

Sarcoidosis is a global disease found in almost all continents. It is a multi-system disorder of unknown aetiology. ${ }^{1,2}$ The pathognomic feature of sarcoidosis is formation of non caseating granuloma, sarcoidosis can involve almost all organs of body but lungs and the lymphatics are the common sites liver, spleen, eyes, CNS and skin are the other common organs affected by sarcoidosis. ${ }^{3}$

sarcoidosis shows epidemiological variations world wide. Important reasons of these variations are- a precise and consistent case definition is lacking, disease presentation is variable, sensitive and specific diagnostic tests are not available, because of these reasons and its resemblance with tuberculosis, sarcoidosis is under reported specially in developing countries. Also the availability of invasive diagnostic technique plays an important role in prevalence of sarcoidosis 4,5

Most of the studies suggest a slightly higher disease rate for women. In a population-based incidence study of sarcoidosis in the United States, rates were 5.9 per 100,000 person-years for men and 6.3 per 100,000 person-years for women In the UK, general practice data have suggested an incidence of approximately 3 cases of sarcoidosis per 100000 people per year. In another UK study, a similar incidence of 5 cases per 100000 people per year was found ${ }^{5,6}$, While study done in a tertiary case respiratory Centre, Delhi sarcoidosis (37.37\%) was most common among 289 patient followed by $\operatorname{IPF}(27.68 \%){ }^{7}$ The true prevalence of sarcoidosis in India is not clearly known as reliable epidemiological data are not available. This study was, therefore, undertaken with the aim to study the clinicoradiological profile of pulmonary sarcoidosis in the Indian context.

Current study objective was to study the clinicoradiological Profile of sarcoidosis in a tertiary care centre.

\section{MATERIAL AND METHODS}

This was a cross sectional prospective observational study which included patients diagnosed to have sarcoidosis in department of pulmonary medicine in lilavati hospital and research centre, Bandra, Mumbai. during the period 20152017. The diagnosis of sarcoidosis was based upon compatible clinical, radiological, laboratory and/or histopathological features as per the joint statement of the American Thoracic Society, the European Respiratory Society and the World Association of Sarcoidosis and Other Granulomatous 
Disorders (ATS/ERS/WASOG) ${ }^{5}$ and also exclusion of any other causes of the same. Patients who are unable to give history or critically ill were excluded from the study.

After taking clearance from ethical committee and informed consent from patients a detailed history was recorded and physical examination was performed in all the patients at the time of initial presentation. Laboratory investigations included haemogram, chest radiograph, and sputum smear examination for acidfast bacilli (AFB), Mantoux test, pulmonary function testing (PFT), electrocardiogram, laboratory tests like serum angiotensin converting enzyme (ACE) levels. Chest radiograph and Contrast enhanced computed tomography (CECT) of chest were performed in all patients. Fibreoptic bronchoscopy (FOB) and transbronchial lung biopsy (TBLB) was performed in patient willing for the procedure and if they were physiologically fit [forced vital capacity $(\mathrm{FVC})>1 \mathrm{~L}$, arterial oxygen tension $(\mathrm{PaO} 2)>60 \mathrm{~mm} \mathrm{Hg}$ on room air]. In patients who were either not fit to undergo $\mathrm{FOB}$ or refused to undergo the same, the diagnosis was made on the basis of clinical, laboratory and radiological features

The patients were classified based on the Siltzbach classification which defines the five stages of the sarcoidosis: Stage 0, which has normal appearance on chest radiograph; Stage 1, lymphadenopathy only; Stage 2, having lymphadenopathy and parenchymal disease; Stage 3, parenchymal disease only; and Stage 4, with parenchymal fibrosis.

Patient with diagnosis of chronic lung diseases like asthma, bronchiectasis, Chronic Obstructive pulmonary Diseases (COPD) requiring treatment intervention and diagnosis and Patients who were not able to perform Pulmonary function test and 6 minute walk test like hemodynamically unstable patients, patients with stroke/bed ridden patients and acute coronary syndrome were excluded from the study.

\section{STATISTICAL ANALYSIS}

Nominal type of Qualitative data was represented in form of frequency and percentage. Nominal type of Qualitative data included sex of the cases, symptoms, clinical signs, CECT chest findings, etc.

\section{RESULTS}

A total of 56 patients who were diagnosed as cases of Sarcoidosis on the basis of contrast enhanced CT chest findings were studied for their clinicoradiological assessment (table 1, table 2).

Mean age of presentation was 46.07 years, among which $64.3 \%$ were female, mean duration of illness before presentation was 23.05 months. Most common presenting complaint was found to be dry cough (85.7 $\%)$, followed by breathlessness (71.4\%), constitutional symptoms like fever, weight loss and anorexia were seen in $21.4 \%$ patients. Arthralgia was seen in $35.7 \%$ patients. skin involvement was found in $8(14.3 \%)$ patients, 52

\begin{tabular}{|c|c|c|c|c|c|c|c|c|}
\hline 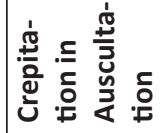 & 粶 & & & & & & 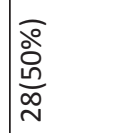 & \\
\hline (َ) & 离 & & & & 量 & & 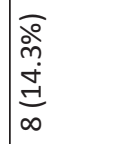 & \\
\hline 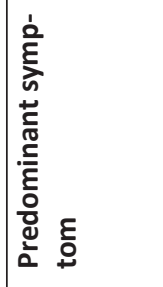 & 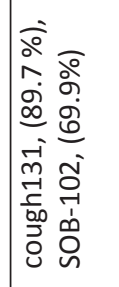 & & 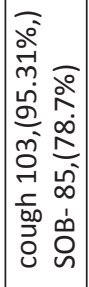 & & 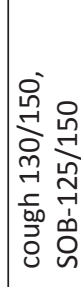 & & 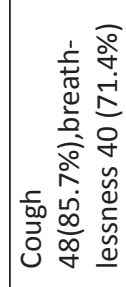 & \\
\hline ह & 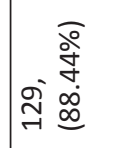 & & 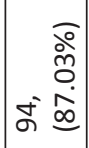 & & $\begin{array}{l}\stackrel{\circ}{2} \\
\text { mi } \\
i n\end{array}$ & 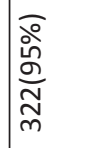 & 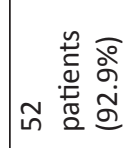 & \\
\hline 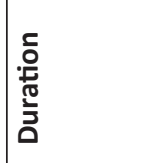 & 员 & & 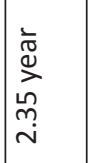 & & & 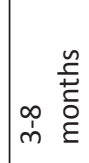 & 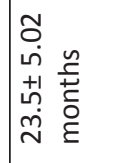 & 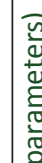 \\
\hline 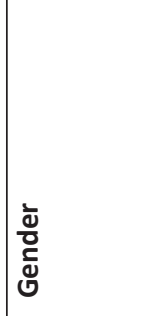 & 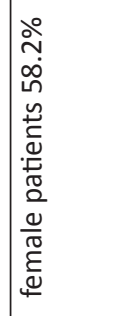 & 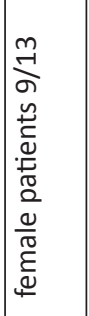 & 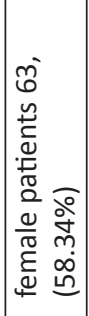 & 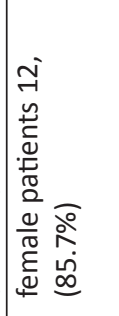 & 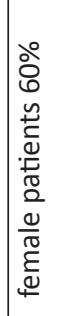 & 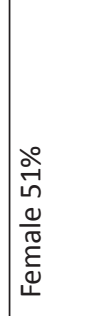 & 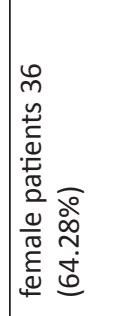 & 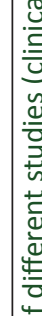 \\
\hline 总 & 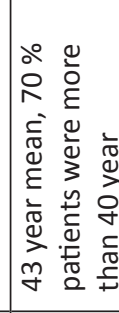 & 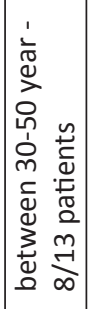 & 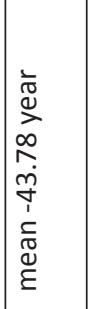 & 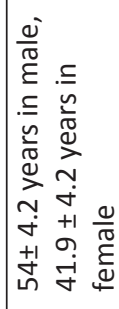 & 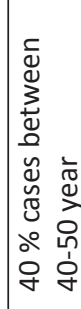 & 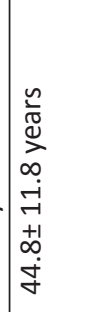 & 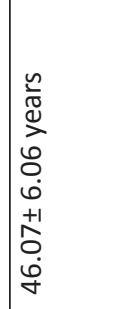 & $\begin{array}{l}\varepsilon \\
\text { g } \\
\dot{a}\end{array}$ \\
\hline 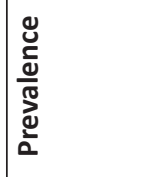 & & 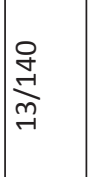 & $\stackrel{\stackrel{\circ}{m}}{\stackrel{m}{m}}$ & 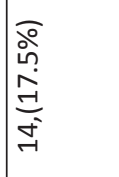 & & 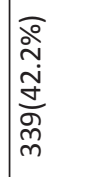 & & \\
\hline 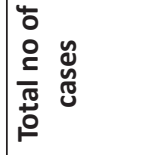 & $\underset{\sim}{\stackrel{O}{-1}}$ & 吕 & $\underset{\sim}{\infty}$ & $\infty$ & 号 & $\tilde{\infty}_{\infty}^{m}$ & in & \\
\hline 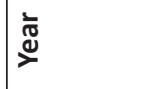 & 공 & 胥 & 总 & $\begin{array}{l}0 \\
\stackrel{1}{0}\end{array}$ & $\hat{\stackrel{D}{~}}$ & 京 & 곰 & \\
\hline $\begin{array}{l}\frac{\partial}{7} \\
\frac{7}{3}\end{array}$ & 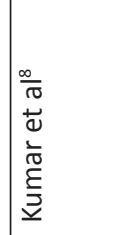 & 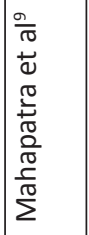 & 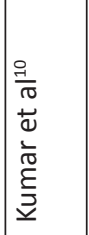 & 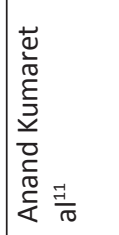 & $\begin{array}{l}\frac{\pi}{\pi} \\
\frac{\pi}{0} \\
0 \\
\frac{\pi}{0} \\
\frac{0}{3} \\
0\end{array}$ & 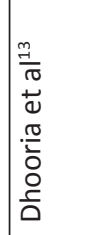 & 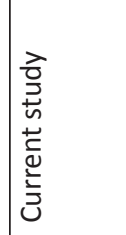 & \\
\hline
\end{tabular}


patients $(92.9 \%)$ were nonsmoker.

Crackles were found in 28 (50\%) patients, all patients (100\%) of sarcoidosis had abnormal chest $\mathrm{x}$ ray, serum ACE level was elevated in $40(71.4 \%)$ patients, $42.9 \%$ patients were misdiagnosed as TB.

\section{DISCUSSION}

In this study mean age in sarcoidosis was $46.07 \pm 6.06$ years. This is in accordance with Indian literature, Kumar et $\mathrm{al}^{11}$ (mean age 43.78 years) and Kumar et $\mathrm{al}^{10}$ (mean age 43 years). Kundu et $\mathrm{al}^{14}$ also gives similar results. The ATS/ERS/WASOG statement ${ }^{5}$ states that sarcoidosis consistently shows a predilection for adults under age 40; peaking in those aged 20-29 years. However, studies ${ }^{5,15}$ done in Scandinavian countries and Japan report a second peak in incidence in women aged over 50 years. Other studies from western countries also report more than $70 \%$ patients of sarcoidosis to be of less than 40 years of age. .,15 $^{2}$ In this study, among 56 patients of sarcoidosis $36(64.3 \%)$ were female patients and 20(35.7\%) were male patients. This is in accordance with Kumar et $\mathrm{al}^{11}$ in which they found $58.34 \%$ female patients. Also, in a study done by Kumar et $\mathrm{al}^{10}$ there were 85 (58.2\%) females but Sharma et $\mathrm{al}^{16}$ found only 39\% females in 210 sarcoidosis patients. Most of the western literature also showed female preponderance, for example study done by Demirkok et $\mathrm{a}^{17}$ found $81 \%$ females in their study.

In this study mean duration of presentation was $23.5 \pm 5.02$ months in sarcoidosis, which is nearly similar to a study done by Kumar et $\mathrm{al}^{18}$, in which they found mean duration of illness in sarcoidosis to be 2.35 years. Also, in a study done by Kumar et $\mathrm{al}^{10}$ the average duration of illness was 20.5 months.

In this study, cough and breathlessness were the most common presenting complains in sarcoidosis. Cough found in 48(85.7\%) patients and breathlessness found in 40 (71.4\%) patients. This is in accordance with Kumar et $\mathrm{al}^{11}$ in which they also observed cough and breathlessness as most common presenting symptoms in sarcoidosis. Also, in a study done by Kumar et $\mathrm{al}^{10}$ the most common presenting symptom was found to be cough, which was present in 131 (89.7\%) patients, followed by exertional dyspnea in 102 (69.9\%). These observations are also in accordance with other Indian studies ${ }^{18,19}$ and with ATS statement on sarcoidosis. ${ }^{5}$

In this study constitutional symptoms (fever, anorexia, and weight loss) found in12 (21.4\%) patients of sarcoidosis. This is in accordance with Kumar et $\mathrm{al}^{10}$ in which they found fever in

\begin{tabular}{|c|c|c|c|c|c|c|c|}
\hline$\underline{a}$ & 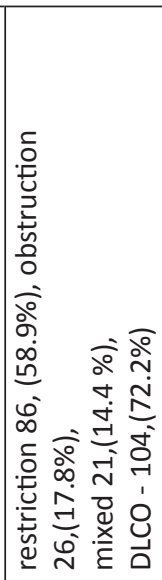 & & 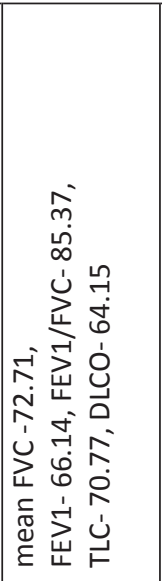 & & 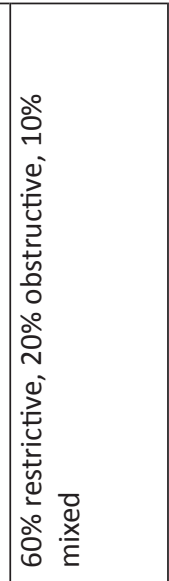 & 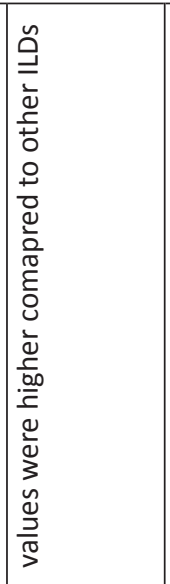 & 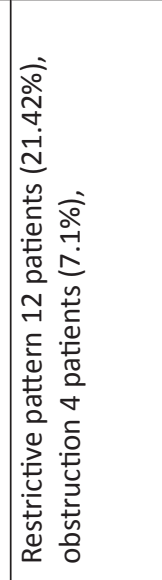 \\
\hline 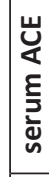 & 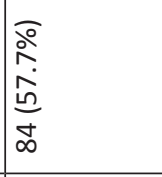 & & 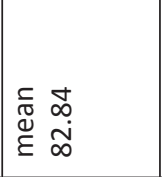 & & & & $\begin{array}{l}0 \\
0 \\
0\end{array}$ \\
\hline 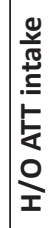 & 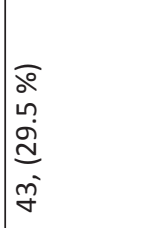 & & 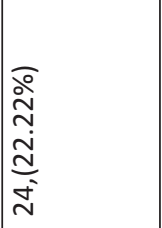 & 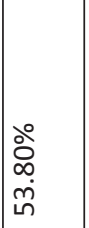 & & $\begin{array}{l}\overline{0} \\
\stackrel{0}{0} \\
0 \\
0 \\
\infty \\
0 \\
0\end{array}$ & 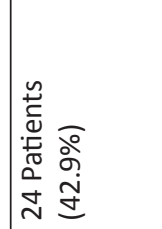 \\
\hline 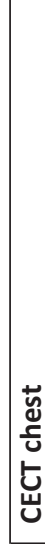 & 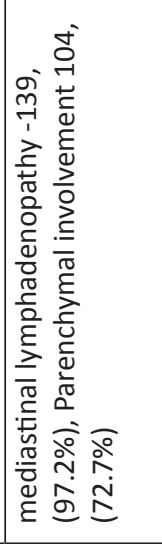 & & 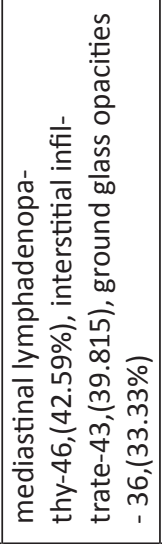 & 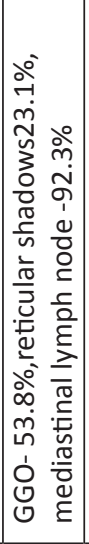 & 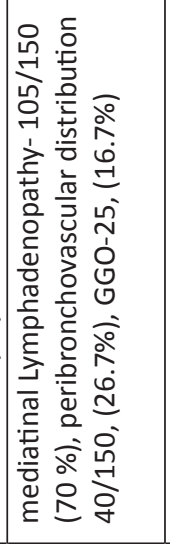 & & 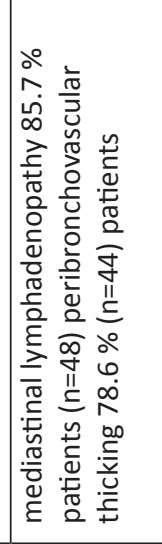 \\
\hline 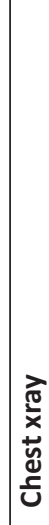 & 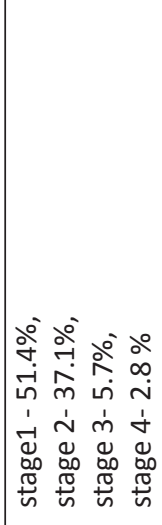 & 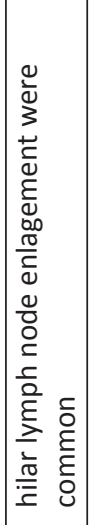 & 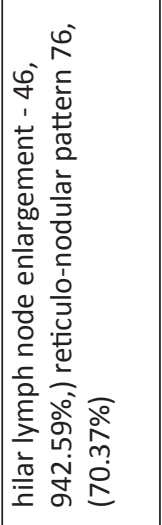 & & 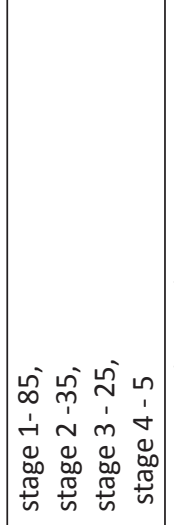 & 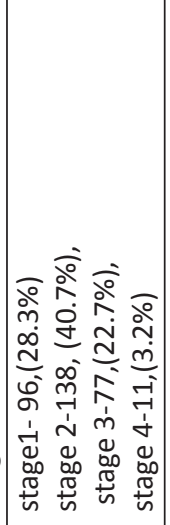 & 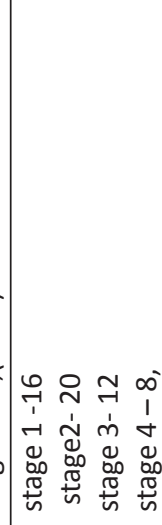 \\
\hline 文 & 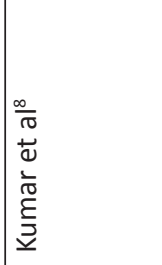 & 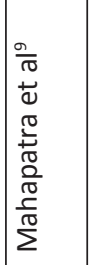 & 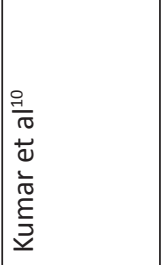 & 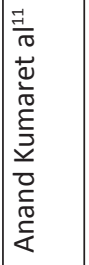 & 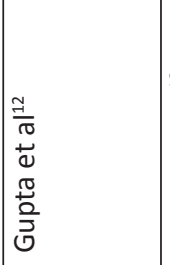 & $\begin{array}{l}\frac{1}{\pi} \\
\frac{0}{0} \\
. \frac{0}{0} \\
\frac{0}{0} \\
0 \\
\frac{0}{0}\end{array}$ & 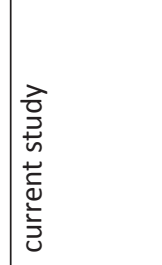 \\
\hline
\end{tabular}


$25.4 \%$ patients, While Kumar et $\mathrm{a}^{11}$ found fever in $11.11 \%$ patients. Old Indian literature also stated constitutional symptoms in sarcoidosis between $14-57 \%{ }^{16,20,21,22,23}$

In this study skin involvement was found in 8 (14.3\%) patients of sarcoidosis, In sarcoidosis skin involvement has been reported to be affected by race, e.g., skin involvement in the form of erythema nodosum is more common in patients of northern European descent. Cutaneous involvement has been reported to occur in $25 \%$ of patients in western countries. ${ }^{5}$ Similarly, ACCESS study group ${ }^{24}$ found prevalence of skin involvement (excluding erythemanodosum) in United States of America to be 15.9\%; erythema nodosum was observed in $8.3 \%$. In Indian study, done by Kumar et $\mathrm{al}^{10}$ cutaneous involvement was seen in $10.3 \%$ patients and none of the patients had erythema nodosum.

In this study 52 patients (92.9\%) were nonsmoker among 56 sarcoidosis patients. This is in accordance with Kumar et $\mathrm{al}^{10}$ in which they found $88.4 \%$ nonsmoker, and Kumar et $\mathrm{al}^{11}$ in which they found $87.04 \%$ nonsmoker among sarcoidosis patients. Kamat et $\mathrm{al}^{25}$ also finds similar findings in non smoker group. In a study done on Turkish population ${ }^{26}, 75$ $\%$ patients were nonsmoker among 293 sarcoidosis patients. Negative correlation between sarcoidosis and smoking was also supported in the ACCESS study ${ }^{27}$

Crackles were found in 28 (50\%) patients of sarcoidosis. which is nearly in accordance with Kumar et $\mathrm{al}^{10}$ in which they found crackles in $49.3 \%$ of patients, but according to ATS statement on sarcoidosis ${ }^{5}$ crackles were present in fewer than $20 \%$ of patients. In later stages of sarcoidosis lung parenchymal involvement occurs more frequently. The difference observed in western literature and this study may be because current study had more number of patients with lung parenchymal involvement.

The chest radiographs reveal abnormalities in more than 90 per cent of the patients with sarcoidosis at presentation ${ }^{16}$ Hilar lymphadenopathy was found in three-fourth cases of sarcoidosis. In this study all patients (100\%) of sarcoidosis had abnormal chest $\mathrm{x}$ ray. Predominant finding in Chest $\mathrm{x}$ ray in sarcoidosis in this study was hilar lymphadenopathy found in 44(78.6\%) patients while only 32 (57.1\%) patients has abnormal lung parenchyma in chest $\mathrm{x}$ ray. According to literature the classic radiographic feature of sarcoidosis is bilateral hilar lymphadenopathy and is reported to be present in nearly three quarters of patients. ${ }^{5}$ In study done by Kumar et $\mathrm{al}^{10}$ Radiographic evidence of bilateral hilar lymphadenopathy was noted in 130 (89\%) patients. Parenchymal infiltrates were seen in 68 (46.6\%) patients with or without lymphadenopathy. This observation is not in accordance with Kumar et $\mathrm{al}^{11}$ who found hilar lymphadenopathy in $42.59 \%$ patients and Reticular/reticulonodular shadow in $70.37 \%$ patients.

Among patients of sarcoidosis in this study most common CECT finding was mediastinal lymphadenopathy found in 48(85.7\%) patients, followed by parenchymal involvement in the form of peribronchovasucular nodule (44 patients, $78.6 \%$ ) associated with few reticulations (40 patients,71.4\%) ground glass opacities(24 patients, 42.9\%) while fibrosis and traction bronchiectasis found in only (8 patients, $14.3 \%$ ). These observations are in accordance with Kumar et $\mathrm{al}^{10}$ in which they also found mediastianal lymphadenopathy as most common finding in 139 (97.2\%) patients, followed by parenchymal involvement in 104 (72.7\%)patients. In western literature, study done by Avital et $\mathrm{al}^{28}$ thoracic lymphadenopathy was the most common finding detected in $89 \%$ patients. Lung parenchyma involvement was seen in $60 \%$ patients. These changes were variable and included: ground-glass attenuation ( $n=39)$, multiple small nodules typically in a peribronchovascular distribution $(n=44)$, irregular thickening of the interlobular septa $(n=16)$.

In this study among patients of sarcoidosis mean FEV1\% (mean \% predicted) was $69.14 \pm 6.31$, FVC\% (mean \% predicted) was $72.36 \pm 6.84, \mathrm{FEV} 1 / \mathrm{FVC} \%$ (mean) was $75.5 \pm$ 8.16 and TLC $\%$ (mean $\%$ predicted) was $74.21 \pm 5.47$ This is in accordance with Indian study Kumar et $\mathrm{al}^{11} \mathrm{FEV} 1 \%$ (mean $\%$ predicted) $66.14, \mathrm{FVC} \%$ (mean $\%$ predicted) 72.71 , FEV1/FVC\% (mean) 85.37, TLC\% (mean \% predicted) 70.77. while study done by Shorr et $\mathrm{al}^{29}$ showed FVC \% predicted $42.6 \pm 13.8$ and FEV1 \% predicted $36.0 \pm 14.4$. The difference between this study and study done by Shorr et al may be because; they performed their study on those advance sarcoidosis patients who were waiting for lung transplantation.

Elevated levels of serum ACE (angiotensin converting enzyme) have been observed in 40 to 90 per cent of patients with sarcoidosis ${ }^{18,20,30}$ and is considered to be a marker of disease activity in reports from the West. In this study serum ACE level was elevated in 40 (71.4\%) patients of sarcoidosis. Kumar et $\mathrm{a}^{10}$ also found high serum ACE levels (>40 U/L) in 84 (57.5\%) patients. There was no significant difference in the SACE activity among different stages in patients with active sarcoidosis. ${ }^{31}$ One of the reasons for these differences could be differences in the protocols followed for ACE level estimation, lack of uniform laboratory standards, and non-availability of a definitive - gold-standard for the confirmation of the diagnosis of sarcoidosis. However, serum ACE has limited utility as a diagnostic test, due to poor sensitivity (false negative results) and insufficient specificity (almost a 10 percent rate of false positive results ${ }^{32}$

On account of high prevalence of tuberculosis in India, many patients with interstitial lung disorders are misdiagnosed to be with tuberculosis, and receive ant tubercular drugs., sarcoidosis was frequently (42.9\%) misdiagnosed as TB. This is nearly similar to study done by Kamat et $\mathrm{al}^{25}$ ) who found history of ATT intake in $31 \%$ of patients, while Kumar et $\mathrm{al}^{11}$ found history of ATT intake only in $14.87 \%$ patients with sarcoidosis as most common entity (22.22\%). In contrary, Kundu et $\mathrm{al}^{14}$ found 64 patients among total 112 patients (57\%), who received ATT.

\section{CONCLUSION}

Sarcoidosis has clinical, radiological and serological manifestations which can vary. Both, clinical and radiological features of sarcoidosis can resemble TB. In developing countries with high prevalence of TB, like India, sarcoidosis is often misdiagnosed as TB. Hence, patients having chronic cough, bilateral hilar lymphadenopathy with or without infiltrates should be investigated for sarcoidosis. 


\section{REFERENCES}

1. Gupta R, Gupta A, Ilyas M, Kalsotra M. Clinicoradiological profile of pulmonary sarcoidosis: A study of 150 patients. Advances in Human Biology. 2017 Sep 1;7(3):119.

2. Baughman RP, Culver DA, Judson MA. A concise review of pulmonary sarcoidosis. American journal of respiratory and critical care medicine. 2011 Mar 1;183(5):573-81.

3. Kumar R, Goel N, Gaur SN. Sarcoidosis in north Indian population: a retrospective study. Indian Journal of Chest Diseases and Allied Sciences. 2012;54(2):99.

4. Nunes H, Brillet PY, Valeyre D, Brauner MW, Wells AU. Imaging in sarcoidosis. InSeminars in respiratory and critical care medicine 2007;28(1):102-120.

5. Statement on Sarcoidosis. Joint Statement of the American Thoracic Society (ATS), the European Respiratory Society (ERS) and the World Association of Sarcoidosis and Other Granulomatous Disorders (WASOG) adopted by the ATS Board of Directors and by the ERS Executive Committee, February 1999. Am J Respir Crit Care Med. 1999;160(2):736-55.

6. Gribbin J, Hubbard RB, Le Jeune I, Smith CJ, West J, Tata LJ. Incidence and mortality of idiopathic pulmonary fibrosis and sarcoidosis in the UK. Thorax. 2006;61(11):980-5.

7. Kumar R, Gupta N, Goel N. Spectrum of interstitial lung disease at a tertiary care centre in India. Pneumonologia i alergologia polska. 2014;82(3):218-26.

8. Kumar R, Goel N, Gaur SN. Sarcoidosis in north Indian population: a retrospective study. Indian Journal of Chest Diseases and Allied Sciences. 2012;54(2):99.

9. Mahapatra QS, Sahai K, Rathi KR, Singh S, Sharma S. Pulmonary sarcoidosis: An important differential diagnosis in transbronchial lung biopsies. Lung India: official organ of Indian Chest Society. 2014;31(2):139.

10. Kumar R, Gupta N, Goel N. Spectrum of interstitial lung disease at a tertiary care centre in India. Advances in Respiratory Medicine. 2014;82(3):218-26.

11. Kumar A, Verma SK, Lal R, Kumar A, Chaudhri S, Prasad R, Kant S. A clinical and radiological profile of patients of interstitial lung diseases, attending the Chest Hospital Of Medical College from North India. Sarcoidosis. 2016;14(6):17-5.

12. Gupta R, Gupta A, Ilyas M, Kalsotra M. Clinicoradiological profile of pulmonary sarcoidosis: A study of 150 patients. Advances in Human Biology. 2017;7(3):119.

13. Dhooria S, Agarwal R, Sehgal IS, Prasad KT, Garg M, Bal A, Aggarwal AN, Behera D. Spectrum of interstitial lung diseases at a tertiary center in a developing country: A study of 803 subjects. PloS one. 2018;13(2):e0191938.

14. Kundu S, Mitra S, Ganguly J, Mukherjee S, Ray S, Mitra R. Spectrum of diffuse parenchymal lung diseases with special reference to idiopathic pulmonary fibrosis and connective tissue disease: An eastern India experience. Lung India: official organ of Indian Chest Society. 2014;31(4):354-60.

15. Nunes H, Soler P, Valeyre D. Pulmonary sarcoidosis. Allergy. 2005;60(5):565-82.

16. Sharma S, Mohan A. Sarcoidosis in India: not so rare. J Indian Acad Clin Med. 2004;5(1):12-21.

17. Demirkok SS, Basaranoglu M, Akinci ED, Karayel T. Analysis of 275 patients with sarcoidosis over a 38 year period; a single-institution experience. Respiratory medicine. 2007;101(6):1147-54.

18. Sharma SK, Mohan A, Guleria JS. Clinical characteristics, pulmonary function abnormalities and outcome of prednisolone treatment in 106 patients with sarcoidosis. The Journal of the Association of Physicians of India. 2001;49:697-704.

19. Shah JR, Hede J, Mathur RS. Diagnostic criteria of tuberculous sarcoidosis. Lung India: official organ of Indian Chest Society. 2009;26(3):86-8.

20. Gupta SK, Gupta S. Sarcoidosis in India: a review of 125 biopsy-proven cases from eastern India. Sarcoidosis. 1990;7(1):43-9.

21. Jindal SK, Gupta D, Aggarwal AN. Sarcoidosis in India: practical issues and difficulties in diagnosis and management. Sarcoidosis, vasculitis, and diffuse lung diseases: official journal of WASOG / World Association of Sarcoidosis and Other Granulomatous Disorders. 2002;19(3):176-84.

22. Kobak S. Sarcoidosis: a rheumatologist's perspective. Therapeutic advances in musculoskeletal disease. 2015;7(5):196-205.

23. Lynch JP, 3rd, Kazerooni EA, Gay SE. Pulmonary sarcoidosis. Clinics in chest medicine. 1997;18(4):75585 .

24. Baughman RP, Teirstein AS, Judson MA, Rossman $\mathrm{MD}$, Yeager $\mathrm{H}$, Jr., Bresnitz EA, et al. Clinical characteristics of patients in a case control study of sarcoidosis. American journal of respiratory and critical care medicine. 2001;164(10 Pt 1):1885-9.

25. Kamat S. A follow up study on interstitial alveolitis. Lung India: official organ of Indian Chest Society. 2004;21(4):41.

26. Musellim B, Kumbasar OO, Ongen G, Cetinkaya E, Turker H, Uzaslan E, et al. Epidemiological features of Turkish patients with sarcoidosis. Respiratory medicine. 2009;103(6):907-12.

27. Newman LS, Rose CS, Bresnitz EA, Rossman MD, Barnard J, Frederick M, et al. A case control etiologic study of sarcoidosis: environmental and occupational risk factors. American journal of respiratory and critical care medicine. 2004;170(12):1324-30.

28. Avital M, Hadas-Halpern I, Deeb M, Izbicki G. Radiological findings in sarcoidosis. The Israel Medical Association journal: IMAJ. 2007;10(8-9):572-4.

29. Shorr AF, Davies DB, Nathan SD. Outcomes for patients with sarcoidosis awaiting lung transplantation. Chest. 2002;122(1):233-8.

30. Sharma SK, Mohan A. Sarcoidosis: global scenario \& Indian perspective. The Indian journal of medical research. 2002;116(1):221-47.

31. Ahluwalia G, Sharma SK, Dattagupta S, Pande JN. Role of transbronchial lung biopsy in diffuse pulmonary disease: a review of 25 cases during one year. The Indian journal of chest diseases \& allied sciences. 1999;41(4):213-7.

32. Ungprasert P, Carmona EM, Crowson CS, Matteson EL. Diagnostic Utility of Angiotensin-Converting Enzyme in Sarcoidosis: A Population-Based Study. Lung. 2016;194(1):91-5.

Source of Support: Nil; Conflict of Interest: None

Submitted: 25-01-2020; Accepted: 16-02-2020; Published online: 14-03-2020 